\title{
LAS NUEVAS MIGRACIONES YUCATANENSES: TERRITORIOS Y REMESAS
}

ESTHER IGLESIAS LESAGA*

\section{Resumen}

La migración internacional es un fenómeno relativamente reciente en el estado de Yucatán; sin embargo, durante la última década, la región se ha convertido en receptora de un importante monto de remesas. Aunque los montos de estos envíos han aumentado significativamente y han servido para mitigar la pobreza, es evidente que no se puede considerar un modelo de desarrollo basado en las remesas; con estas se cubren necesidades de sobrevivencia y es sólo en algunos casos que puede hablarse de un aumento en la calidad de vida, manifestado mediante una acumulación de salarios. La actual documentación para el análisis de algunos de los indicadores es aún incipiente; sin embargo, con el trabajo de campo de corte histórico que aquí se presenta —en el que se analiza cómo ha influido en la experiencia de los inmigrantes el proceso de migración interna detonado por el desarrollo del complejo turístico cancunense-, así como con una revisión de las condiciones en los nuevos territorios expulsores - especialmente los de la región henequenera-, se complementan algunas de las interrogantes planteadas.

Palabras clave: migración, remesas, territorio, crecimiento, Yucatán.

* Investigadora Titular del Instituto de Investigaciones Económicas de la UNAM; Investigadora Nacional (SNI, Conacyt). 


\begin{abstract}
Although international migration is a relatively recent phenomenon in the State of Yucatan, during the last decade the region has received important amounts of remittances. While these remittances have grown significantly and have served to mitigate poverty, it is evident that they cannot be considered the bases of a development model. They cover the needs for survival, and only in some cases it is possible to speak of an increase in the quality of life, manifest in the accumulation of salaries. Actual documentation for the analysis of relevant indicators is still incipient. Nevertheless, the historical fieldwork presented here - which analyzes how the internal migration process sparked by Cancun's resort development has influenced migrant experience - , combined with a review of the conditions in labour-expelling areas (especially the henequen producing region), serve to shed light on this situation.
\end{abstract}

Keywords: migration, remittances, territory, growth, Yucatan. 


\section{TRANSFORMACIONES SOCIOECONÓMICAS EN YUCATÁN ${ }^{1}$}

$\mathrm{E}$ 1 estado de Yucatán, ubicado en el sureste de México, tiene una extensión territorial de 39,612 km; dentro de este territorio hay que resaltar los $342 \mathrm{~km}$ de litorales. El estado, además, aporta el 1.42\% del PIB nacional (INEGI, 2010:34). Según el Instituto Nacional de Estadística, Geografía e Informática (INEGI), para 2005, Yucatán contaba con 1,818,948 habitantes, de los cuales $49.30 \%$ eran hombres y el restante 50.70\%, mujeres (INEGI, 2005: 1); en la actualidad la entidad federativa cuenta con un total de 1,955,577, siendo 992,244 mujeres y 963,333 hombres (INEGI, 2010). La mayor concentración poblacional de esta entidad de la República mexicana se encuentra en su capital, Mérida, en donde habitan 830,732 personas, es decir, el 42.48\% del total del estado. En esta ciudad, al igual que al interior del estado, se mantiene una proporción muy equilibrada entre ambos sexos, aunque sobresale el 51.68\% de mujeres sobre los hombres: esto último tiene que ver, seguramente, con la reciente migración de mano de obra femenina que en la actualidad se emplea no sólo en algunas labores domésticas, sino también en las maquiladoras y en el sector servicios de su hotelería.

Yucatán, que en el ámbito nacional representa apenas el $2 \%$ de la superficie total del país, es de hecho una de las entidades nacionales con un porcentaje muy alto de población indígena o mestiza (65.5\% para 2000). También es uno de los espacios que ha guardado su lengua vernácula -el maya - con gran intensidad y permeabilidad en el español, en comparación con las lenguas vernáculas del resto del territorio nacional.

Aunque los procesos migratorios en el nivel transfronterizo de la península de Yucatán datan ya de algunas décadas atrás, la migración trasnacional yucatanense es de hecho la más reciente dentro del espacio nacional; no obstante, los movimientos migratorios nacionales y trasnacionales representaban en 2004 casi 9\% del total de la población del

1. Este trabajo fue presentado en su primera versión - y solamente como ponencia- en el Simposio 3 Importancia Económica y Social de las Remesas, en el Primer Congreso Latinoamericano sobre Migración Internacional "Voces del Sur", en el Centro de Investigación y Estudios Avanzados de Población de la Universidad Autónoma del Estado de México, del 12 al 14 de noviembre de 2008, Toluca, México. 
estado (157,339 personas) (INDEMAYA, 2004)² (cf. cuadro 1). De este último total, 37.601 (24\%) son migrantes trasnacionales. En la actualidad se ha ido engrosando de manera muy singular el número de esta migración que desde el estado de Yucatán se dirige a diferentes estados de Estados Unidos.

En los años treinta, concretamente en 1937, cambian las relaciones sociales de producción, en tanto que se incorpora la reforma agraria cardenista, momento en el que 150 mil personas fueron sacudidas por nuevos bríos para convertirse en los beneficiarios de derechos del nuevo ejido colectivo.

Junto con el reconocimiento de la importancia de la reforma agraria, también hay que tener presente el hecho de que cercenó las posibilidades de gestionar las unidades productivas al reinaugurar el paternalismo antes entre propietario y peón, ahora entre ejidatario y Estado- Recordemos también que se seguía retrasando la aparición de la mujer dentro de la esfera productiva; los únicos que tenían derecho a engrosar las filas de nuevos ejidatarios eran los hijos varones. En consonancia, tampoco hay que olvidar que la mujer, reproduciendo funciones sexistas, siempre estuvo más preocupada por alfabetizar a sus hijos que a sus hijas.

Hacia finales de la década de 1960, la mujer del espacio rural de Yucatán se convierte en clientela política codiciada. Un gran malestar social se anticipaba entonces en la región más importante del estado, la región henequenera, que en los albores de los años setenta empieza a manifestar, aunque de manera aislada, algunas protestas sociales. Las mujeres del ejidatario henequenero resentían, en su papel de quien compra mercancías, la crisis en su economía doméstica debido a la disminución del número de jornadas de trabajo en las que eran contratados sus esposos e hijos ejidatarios. Es precisamente durante esta coyuntura de los años setenta que la región henequenera en crisis decide el futuro de la gran

2. Indemaya constata que en 2006 se otorgaron 4,341 matrículas para yucatecos en 39 ciudades de Estados Unidos. La ciudad de San Francisco representa el 34\%, los Angeles, el 19\%, Oxnard, el 9\%, Portland, el 7\%. Aunque para 2007 disminuyó el número de solicitudes de matrículas, las ciudades de destino de los migrantes yucatecos a Estados Unidos siguen siendo las mismas (Indemaya, 2010:1-2). Agradezco el apoyo recibido por la Directora de esta institución y el de algunos de sus más cercanos colaboradores,por el material documental proporcionado y el apoyo logístico que nos ha permitido ya en dos ocasiones realizar algunos de nuestros trabajos de campo. 
mayoría de las familias rurales y que, a nuestro entender, representa el inicio de un cambio de conducta en el tronco matriarcal: la mujer de este espacio henequenero, "salvaguarda de los usos y costumbres de la comunidad", manifiesta cambios significativos en sus patrones de conducta.

En este camino hacia la transición - en donde el matriarcado tiene tanto que explicar en la conservación de conductas identitarias de las comunidades rurales de Yucatán-, habría que agregar también que, simultáneamente al proceso de deshenequenización, se suma el auge de los llamados polos costeros de desarrollo en lo que denominamos el espejismo cancunense que, aunque al comienzo de su construcción atrajo las primeras oleadas de migrantes, la mayor parte de ellos hombres dedicados a la albañilería, posteriormente, recibió oleadas de migrantes temporales provenientes no sólo de la zona henequenera, sino de otros espacios rurales de Yucatán, esta vez con mayores contingentes de mano de obra femenina, que por lo general desarrollaba labores domésticas. En etapas posteriores, y ya con una mejor calificación, las mujeres se ocuparían en el sector administrativo y de servicios de la hotelería de gran turismo.

En este desarticulado espacio económico llega a Cancún, principal centro de desarrollo de la Riviera maya, el primer flujo migratorio proveniente de los principales municipios de la antigua región agavera. En su mayoría son hombres que se van a dedicar a la construcción; más tarde, ellos o sus descendientes se incorporarán a algunas de las ocupaciones en el sector de servicios (Re Cruz, 1996:167-181). ${ }^{3}$ Diferentes oleadas

3. El estudio de Alicia Re Cruz devela cómo a través de las diferentes oleadas migratorias de una comunidad, concretamente la de Cham Kom, se manifiesta una gran diversidad socioeconómica de acuerdo con las diferentes etapas y relaciones sociopolíticas que acompañan a los primeros migrantes que llegan a Cancún desde finales de los años setenta. Los primeros migrantes hicieron realidad su sueño: se convirtieron en pequeños empresarios y detentores del poder político de su comunidad. Las subsiguientes generaciones tuvieron que sujetarse a los que a partir de ese momento se denominaban a sí mismos como "los de Cancún", quienes para el pueblo milpero de Cham Kom eran los que habían logrado "la meca del éxito económico". Este bosquejo analítico del Cham Kom de los años noventa presenta dos mundos diferentes, yuxtapuestos, cuyo resultado no es ni síntesis ni homogeneidad social. Estos dos mundos, el del campesino y el del emigrante, expresan diferentes experiencias con la migración, a través de representaciones culturales. Imágenes, símbolos y representaciones como la de la milpa son recreados como respuesta al contexto socioeconómico y político del momento. 
migratorias posteriores van incorporando, cada vez en mayor medida, la mano de obra femenina. Las mujeres, a pesar de despojarse de sus vestimentas tradicionales, conservan todavía - en muchos casos- rituales, leyendas y metáforas de ciertas concepciones de la memoria cultural de los mayas yucatecos (Rosales Mendoza, 2009:117-118). Después la "grieta", se ensancha hacia aquellos otros espacios rurales que no ven solucionado ningún desarrollo económico local que les permita sobrevivir y mejorar su calidad de vida en los mismos.

Es a partir de estas consideraciones previas que pretendemos plantear algunas de las aristas de la más reciente de las migraciones internacionales del país.

\section{ADELGAZAMIENTO DEL APARATO DEL ESTADO Y DESARTICULACIÓN DE LA REGIÓN RURAL YUCATANENSE}

El desgaste de la institución ejidal en México se había ido gestando internamente y se aceleró a medida que el Estado nacional se alejaba en tanto que interceptor e intermediario en relación con el apoyo crediticio.

El caso del ejido henequenero de Yucatán fue un ejemplo muy relevante al respecto. La década de los ochenta marcó para México el parteaguas en el que se diseñaron las transformaciones más importantes del modelo económico del Estado nacional: es la bisagra histórica en la que el país comienza el camino hacia la desregulación y el adelgazamiento del aparato del Estado. También es el momento en el que se signan los destinos de una gran parte de la población de sus espacios rurales.

El estado de Yucatán, que para finales de los noventa representa apenas el 1.30\% del PIB nacional (INEGI, 2003:40), fue uno de los espacios elegidos para activar esta política económica y, según nuestro criterio, fue seleccionado específicamente como el escenario de pruebas para medir la docilidad y aceptación de la mano de obra asalariada a bajísimos costos por parte del capital internacional, expresado en este caso por medio de las maquiladoras. La desarticulación de un área rural en agonía institucional y en incapacidad económica para competir en productividad y precios en el libre mercado fueron los insumos necesarios 
y suficientes para llevar a cabo el desmantelamiento de esta región. En los últimos años del siglo pasado, el antiguo espacio henequenero lucía ya, en su gran mayoría, como tierras ociosas invadidas por la vegetación espinosa y de matorral entre las que aparecían, como lunares, algunas áreas de cultivos de henequén pertenecientes a los llamados "parcelarios"; desde tempranas horas de la madrugada, los pueblos de Teya, Chapab, Sacalum, Abala, Tetiz, Kinchil, Ucú, Timucuy, Bokobá, por mencionar sólo algunos, expulsan a una población que regresa por la tarde a estos mismos pueblos, ahora convertidos en pueblo dormitorios (Iglesias Lesaga, 2000:10).

Yucatán necesitaba ocupar mano de obra emergente del espacio henequenero y ofrecía al capital internacional una fuerza laboral abundante, dócil, barata (en las maquiladoras de la frontera norte se perciben salarios que representan el doble del salario percibido en Yucatán); esto permitió altas tasas de rotación entre sus trabajadores (Castilla Ramos y Torres Góngora, 1998:106-112; Gravel, 2006:51-66).

Las empresas planificaron la absorción de la mano de obra en un momento de transición hacia el cambio de conducta de los poblados rurales: se acercaron a estos e instalaron, si no en todos, sí en una gran mayoría de los poblados de la antigua zona henequenera, la mayor cantidad de estas maquiladoras (Ramírez Carrillo, 2006:7-10). ${ }^{4}$ Desde 1995, la política industrial de Yucatán sigue privilegiando la vía neokeynesiana como la única para generar crecimiento económico.

\section{PARTICULARIDADES DEL FENÓMENO MIGRATORIO EN YUCATÁN}

El problema migratorio en Yucatán comprende dos espacios analíticos diferentes: uno que abarca la migración interna tanto en el estado, como hacia el vecino estado de Quintana Roo; otro que se refiere al flujo que se dirige en su mayor parte hacia Estados Unidos, principalmente al estado de California.

4. A través de su obra, el autor recorre las diferentes etapas en la instalación de las maquiladoras en este estado de la república en décadas recientes y realiza una caracterización de las mismas. 
De acuerdo con información reciente del Instituto para el Desarrollo de la Cultura Maya del Estado de Yucatán (NDEMAYA) (2010:2-14), la migración interna se dirige esencialmente hacia dos destinos principales: la ciudad de Mérida y el estado de Quintana Roo. Esta migración se caracteriza por ser mayoritariamente de género masculino, aunque incluye también la migración femenina que, según este mismo estudio, no rebasa el 20\% del total. La media de edad de los migrantes es de entre 25 y 29 años; más de un 60\% de ellos son hablantes de maya. En su mayoría, se ocupan en su lugar de destino, y de manera muy semejante en uno u otro lugar de llegada, en labores de construcción, cocina y limpieza. En la mayor parte de los casos se da un retorno periódico a sus comunidades de origen, sobre todo los que trabajan en Mérida, ciudad que se ha convertido en el principal foco de atracción como mercado laboral. ${ }^{5}$

El fenómeno migratorio tiene muchos rostros y diversas aristas para su abordaje. Este fenómeno, y más concretamente el inmigratorio, supone desde un comienzo su ubicación entre un punto de partida y otro punto de llegada. Si a ello agregamos que pretendemos estudiar la inmigración de una región con un crecimiento marginal en sus tasas de crecimiento económico y enormes carencias en la desigualdad social y si, a su vez, este problema pertenece a un espacio de bajo desarrollo económico en el país, como es el caso que hoy nos ocupa, el del sureste de México y más concretamente el de la inmigración internacional yucatanense, cerramos aún más nuestro círculo de acotamiento para encuadrar adecuadamente el objeto de estudio.

La migración trasnacional del estado de Yucatán, a pesar de ser una de las migraciones trasnacionales más tardías en el territorio mexicano, es portadora de un background del que adolecen la mayoría de los migrantes de otras regiones del país: la experiencia de trabajo en el

5. De este estudio de Indemaya hemos extraído únicamente algunos porcentajes generales puesto que es una encuesta levantada para un número determinado de casos y sólo nos permite precisar algunas tendencias en este movimiento migratorio; por lo mismo, no podemos individualizar el tipo de labores en estos dos espacios que ocupan, por una parte, personal altamente calificado para la hotelería, y por la otra, personas que desarrollan una multiplicidad de labores relacionadas con el turismo. Tampoco incluimos aquí para su análisis otros indicadores que se refieren al lugar de origen y destino de los migrantes, por el propio universo que comprende la encuesta. 
mercado turístico cancunense y en el de la Riviera maya. Es importante subrayar que, a diferencia de la migración de la zona tradicional expulsora del país (Aguascalientes, Colima, Durango, Guanajuato, Jalisco, Michoacán, Nayarit, San Luis Potosí y Zacatecas), el estado de Yucatán inaugura -según las escasas investigaciones con las que se cuenta en la actualidad sobre el tema- su primer grupo migratorio internacional a mediados de los setenta (Ojeda Cerón, 1988). No obstante, es recién en los años ochenta cuando se deja sentir ya la presencia de migrantes yucatecos en Estados Unidos, aunque huelga decir que décadas antes ya habían migrado temporalmente los primeros contingentes de los diferentes Programas de Braceros.

Esta migración tiene características muy peculiares que, a nuestro parecer, son inherentes a la condición de marginalidad de su propio espacio rural y que en gran medida comienza a agonizar más tarde que otros espacios rurales del país que ya estaban desapareciendo. Como mencionamos en el apartado anterior, la antigua zona henequenera, principal espacio productivo, y en donde se concentra la mayoría de la población del estado de Yucatán, entró en severa decadencia a principios de los años sesenta, a los que siguieron dos décadas en las que se va adelgazando la población, en el mismo momento en que se empieza a construir el "polo" turístico cancunense. Esa experiencia de trabajo en Cancún y después en la Riviera maya acrecienta una calificación y un modus vivendi hasta entonces desconocido por las comunidades rurales y la población proveniente de las zonas urbanas, especialmente de la capital del estado de Yucatán.

Sin embargo, explicar la migración hacia Cancún sin considerar el peso que representan los fenómenos naturales, como los dos grandes huracanes -Gilberto en 1988 e Isidoro en 2002- no alcanzaría para comprender la importancia que adquiere la inmigración trasnacional, proveniente de Yucatán, durante está última década. Ambos fenómenos naturales desestructuraron el espacio rural; en el caso de Gilberto, no sólo se vio afectada la zona henequenera, ya en agonía, sino también el espacio apícola, actividad tradicional de la cultura maya, y en gran 
medida la incipiente industria pesquera de entonces. ${ }^{6}$ Recordemos que una industria pesquera mucho más fortalecida fue devastada posteriormente, entre otros espacios, en las costas de Sisal por el otro huracán, Isidoro. Estos fenómenos naturales - de los que aquí sólo hemos señalado dos de los más importantes- devastaron cultivos y empresas, pero también, como una gran ironía, la infraestructura hotelera, la cual fue ampliamente reestructurada en ambas ocasiones, situación que sirvió como solución para quienes buscaban mano de obra en la construcción $y$ en el sector de servicios.

\section{MIGRACIÓN TRANSNACIONAL}

Veo la migración como una manera de armarse para traer beneficios, para prevenir la migración.

NAOMI AdELSON

Los primeros antecedentes de la migración trasnacional yucateca, básicamente migración hacia Estados Unidos, se remontan hacia poco antes de la década de los ochenta. Su destino para ese entonces parece haber sido la ciudad de Los Ángeles, Ca., y los condados aledaños. En la actualidad, y de acuerdo con la única encuesta que hoy existe sobre este fenómeno, la migración de origen yucateco se ha extendido a lo largo del

6. Respecto del impacto del huracán Gilberto en la zona es muy ilustrativo el siguiente texto de Iglesias: "El meteoro ocasionó la perdida de 55,000 hectáreas de cultivo en el estado de Yucatán por un valor aproximado de $\$ 16,000,000,000.00\left({ }^{*}\right)$ desaparecidos casi en su totalidad (80\%) los cultivos de hortalizas, maíz, sorgo, fríjol, sábila, cacahuate, arroz, frutícolas y otros. El gobierno del estado de Yucatán apresuró hoy a poner en marcha un programa de resiembra en un momento que cunde ya el desaliento entre los campesinos..." “(...) Los daños ocasionados al sector pesquero son cuantiosos: Dzilam Bravo, y Telchac Puerto son apenas dos ejemplos entre muchos otros. Durante la semana siguiente al huracán solamente en Celestún se calcularon alrededor de $\$ 14,000,000.00$ diarios de pérdidas derivadas de la no captación diaria de pesca. La paralización de los establecimientos industriales de harina de pescado, congeladoras distribución del producto y pérdidas del que se encontraba congelado en las instalaciones al momento del huracán (Iglesias, 1988)." (*) Las cantidades aquí expuestas se expresan en la moneda corriente de entonces. 
territorio de Estados Unidos (Indemaya, 2004). ${ }^{7}$ En 2004, del total de migrantes originarios de Yucatán, el 77\% estaba instalado en California, 9\% en Oregon, 6\% en Colorado; los estados de Texas Nevada, Washington, Springfield Missouri, Utah y Florida contaban cada uno de ellos con $1 \%$ del total, mientras que el restante $2 \%$ lo componían migrantes de quienes no fue posible identificar su lugar de destino.

Para 2004, los totales a los que estamos haciendo referencia arrojan un flujo migratorio de 37,601 migrantes, de los cuales 36,803 - es decir, $98 \%$ - se van a Estados Unidos. En la actualidad, de acuerdo con los últimos estudios, se detectan ya 45,000 migrantes originarios de $101^{8}$ municipios del estado de Yucatán.

Las características más sobresalientes de la migración trasnacional desde Yucatán, de acuerdo con nuestras observaciones, se jerarquizan en función de los siguientes indicadores:

1. Tardía en el ámbito nacional. Proviene básicamente del alto número de desocupación del espacio rural, comenzando por la antigua zona henequenera y los residuos de mano de obra desocupada que dejó de absorber tanto el estado de Yucatán en sus espacios rurales, como la Riviera maya en su desarrollo turístico. También proviene de la mano de obra que no encontró espacio en las maquiladoras.

2. Antigüedad muy reciente, pues se remonta a finales de los años setenta y principios de los ochenta.

3. Poco representativa por el número de migrantes involucrados, pero extremadamente ligada a sus comunidades y familias de origen, tal y como se nota en la curva de frecuencia de envíos ${ }^{9}$ que generalmente son mensuales y, en muchos

7. Quiero dejar testimonio del invaluable apoyo de la licenciada Estela Guzmán, al proporcionarme las fuentes que nos han permitido cruzar la información estadística para obtener algunos resultados mencionados en este y otros apartados del presente trabajo.

8. Hasta el presente, falta contabilizar cinco de los más poblados municipios del estado: Mérida, Tizimin, Uman, Kanasin y Valladolid. Exponen diagnóstico por fenómeno de desplazamiento demomo (SIPSE, Grupo Milenio, Mérida, Yucatán, 2010, http://www.sipse. com/noticias/40779-bajan-23-remesas-yucatecos--.html ) .

9. Aunque el monto de remesas se ha reducido durante 2010 - debido a la crisis y la desocupación en Estados Unidos-, ha aumentado la frecuencia en los envíos de dinero, y sigue llegando a las comunidades de origen una ayuda familiar importante. ${ }^{\star}$ En el estu- 
casos, quincenales, aunque se consigan también envíos semanales a diferentes localidades de los municipios que detentan una mayor tasa de expulsión.

4. Inmersa en la nueva oleada de la creciente diversificación regional del nuevo flujo migratorio nacional.

5. Incremento en la participación de jóvenes, en su mayoría varones, que dejan sus comunidades, muchos de ellos a partir de los 16 o 17 años. En la actualidad, no existe información estadística extensa vinculada al género para el caso del estado de Yucatán, y lo que consignamos aquí se basa en diferentes estudios de campo. Teniendo en cuenta que estos jóvenes son en su mayoría mano de obra de muy baja calificación que no encuentra trabajo ni ve futuro en el espacio rural, es necesario considerar el factor "contagio" o "probar suerte" como una de las razones últimas para migrar.

6. Posee rasgos comunes o inherentes - por lo menos, en el primer flujo migratorio- en todas las comunidades de origen: en cada una de ellas ha existido un "motor de arranque" que les ha permitido ser el receptáculo de nuevos migrantes hacia el destino trasnacional. ${ }^{10}$

7. Guarda semejanza con la migración trasnacional mexicana: al igual que en otros espacios del territorio nacional, los migrantes trasnacionales yucatecos "más exitosos" son aquéllos que tuvieron una primera experiencia en migración interna y en espacios que tenían contacto con otras culturas. En este

dio de casos que presenta actualmente INDEMAYA-COBAY-UTM, "Estudio regional de la Migración en Yucatán", se consignan en dos espacios de estudio encuestados que las remesas generalmente alcanzan una media de \$2,000 mexicanos mensuales y, sólo excepcionalmente en ciertos poblados, se recibe hasta un $60 \%$ más en el monto de sus remesas familiares.

10. En diferentes trabajos de investigación que incluyen trabajo de campo se consigna la presencia de quienes fueron migrantes pioneros, que nosotros llamamos "motores de arranque" que habrían actuado como receptores, sobre todo en el país de destino. "Cuando llegué por primera vez a San Francisco en 1988, no había nadie de Yucatán aquí en San Francisco, cuando mucho había veinte de nosotros..., pero hace algunos años, todos los muchachos comenzaron a salirse del pueblo para venir acá" - afirma Santos Nic, profesor de primaria, de 51 años, que llegó en 1978 y que ha sido adoptado extraoficialmente por la comunidad como su líder-. "Llegamos en busca de oro a California" — dice Jorge"pero sin el profesor no lo hubiéramos logrado. Nos cuenta historias sobre nuestra tierra... hablamos maya entre nosotros y si alguien necesita un intérprete, entonces lo ayudamos". Otro caso significativo es el caso del propietario del restaurante "Tommmy's", en la avenida Geary, quien, proveniente de Oxkutzcab, llegó a San Francisco por medio de un programa bracero y en los años sesenta trajo a toda su familia nuclear, a la que se le fue sumando su familia extensa. "Para muchos de los inmigrantes mayas recién llegados, Tomás, es su familia" (Garance Burke, "Indígenas mexicanos migrantes en Estados Unidos"). 
sentido, el ejemplo más significativo para los yucatecos es el caso de Cancún y de la Riviera maya que habría actuado a manera de "escuela" o "trampolín" para migrar posteriormente a Estados Unidos (Cornelius, Fitzgerald y Lewin, 2007). ${ }^{11}$

8. El cambio de credo religioso en una parte importante de los migrantes habría actuado en relación directamente proporcional con los cambios de conducta, sobre todo en el control para el consumo de alcohol, que antes estaba "moderado" por la presencia de la familia, aunque en la actualidad es difícil hacer una evaluación debido a la falta de información e investigación a ese respecto.

9. Los cambios en la relación de la familia nuclear - sobre todo en las últimas oleadas migratorias - le otorgan a la mujer una acción decisiva para influir en la inclusión de la joven hija o la joven esposa para formar parte de la mano de obra requerida por el mercado internacional.

10. Si bien comenzó en algunos espacios rurales de la antigua zona henequenera, en la actualidad la migración se ha extendido a la antigua zona rural citrícola-maicera, ganadera, y otras, ${ }^{12}$ abarcando también las poblaciones urbanas más importantes del estado.

11. Emana básicamente de los espacios rurales y obedece, según los más recientes estudios, ${ }^{13}$ a la misma tendencia de flujos migratorios trasnacionales provenientes de México y desde diferentes regiones del país.

11. Esto puede observarse en detalle en el artículo de Rodríguez, Wittlinger y Manzanero, "The interface between Internal and International Migration", en Cornelius, Fitzgerald y Lewin (2007), Mayan Journeys: The new migration from Yucatan to the United States.

12. Es el caso de Tunkás; los impactos en la entidad provocados por la migración son tan importantes, que incluso han transformado el municipio en un espacio tradicional de expulsión. Hoy, debido a las pocas oportunidades de trabajo que ofrece su localidad, ese espacio tradicionalmente maderero y de artesanías de muebles es uno de los focos expulsores más representativos de Yucatán; a su vez, una gran mayoría de su población ha cambiado al credo evangélico y esto les ayuda en su espacio de destino (Travis Silva et al., 2007:29-48; García y Romero, 2007:115-139).

13. Los cambios ocurridos en la composición urbano/rural de los migrantes mexicanos a Estados Unidos en las últimas décadas, que en términos generales se caracterizan por una transición de altas tasas de participación de migrantes urbanos durante la década de 1980, a bajas tasas de participación de estos migrantes en la década de 1990, refleja la complejidad y dinamismo de la migración mexicana a Estados Unidos. La reciente "ruralización" del flujo migratorio no puede considerarse como una transformación definitiva; el hecho de que ciertas tendencias se reviertan en tan corto tiempo, como parece suceder con la composición urbano/rural de los migrantes en los años noventa, expresa más bien la necesidad de generar nuevos marcos interpretativos, menos rígidos, que permitan entender y dar cabida a situaciones aparentemente inesperadas (Lozano, 2001:11). 
12. El origen de los migrantes, que en una gran mayoría obedece a comunidades bilingües maya-español, no incide directamente en el decrecimiento del flujo de personas de esta migración trasnacional. ${ }^{14} \mathrm{Al}$ contrario, consideramos que la "marginación" que sufren muchos de estos migrantes en Estados Unidos, en tanto que indígenas, se neutraliza a partir del intercambio en su lengua vernácula y crea lazos más fuertes entre las diferentes comunidades mayas que sirven para acrecentar nuevos flujos migratorios.

13. Los llamados "nichos laborales para inmigrantes mexicanos" se reducen aún más para la migración trasnacional de Yucatán que para los migrantes de las zonas tradicionales y las del norte de México: la docilidad de la mano de obra de Yucatán encauza a estos migrantes de baja calificación laboral hacia los empleos menos remunerados.

14. La migración trasnacional proveniente de Yucatán empieza a manifestar signos de vulnerabilidad en los problemas de salud mental: depresiones, drogadicción y, más recientemente, delincuencia, amenazan a una parte importante de las últimas oleadas migratorias.

\section{LOS PORQUÉS DE LA MIGRACIÓN: SOBREVIVENCIA SIN DESARROLLO}

Entre las razones que llevan a las comunidades referidas a emigrar a Estados Unidos, aparece en primer lugar el hecho de que no sólo tenían familiares o miembros de su comunidad que en años anteriores habían migrado y realizado "exitosamente" el sueño americano, sino que éstos

14. Se observa que, efectivamente, en la medida en que los municipios están habitados en mayor porcentaje por población indígena, es menor el número de emigrantes internacionales declarados en ellos, lo que permite suponer una menor incidencia de la emigración internacional en los municipios con población mayormente indígena. No obstante, con este trabajo se aclara que en algunas entidades, como en el caso de Yucatán, y de acuerdo con el Censo General de Población y Vivienda de 2000 (INEGI), existen municipios en los que se declaran nulos los emigrantes internacionales, precisamente aquellos cuyo $60 \%$ de la población es de habla indígena. A nuestro parecer, se trata de un error de la propia concepción del Censo y obedece, entre otras razones, al temor de suministrar datos por parte de las comunidades expulsoras del número de migrantes que tienen en las mismas. Las razones son diversas y escapan a la dimensión de esta ponencia. En este sentido, es interesante consultar el artículo "La migración de la población hablante de lengua indígena en el sureste mexicano”, de Darío Antonio López Villar, publicado en la revista electrónica Población y Salud en Mesoamérica. 
ofrecían trabajo en sus restaurantes como lavaplatos o como meseros, o los integraban con otros miembros de las comunidades latinas para ocuparse en algunos trabajos agrícolas. Existen también otros móviles muy importantes entre los que destacan las posibilidades de ganar más para mantener con una nueva calidad de vida a su familia nuclear o extensa. Un ejemplo claro de ello son las nuevas construcciones de material que van remplazando la casa maya sin destruir totalmente su tradicional modus vivendi. Hacia finales de los años noventa, las transformaciones paulatinas en el hábitat rural del estado de Yucatán se manifestaban más significativamente en la antigua zona henequenera $;{ }^{15}$ en la actualidad aparecen más marcadamente en la antigua zona citrícola como producto - en gran medida - de la elevada tasa migratoria internacional de estos espacios y de un importante aumento en los montos de remesas de sus migrantes. En un reciente y breve trabajo de campo en el municipio de Oxkutzcab y en los poblados cercanos a la cabecera municipal, como es el caso de Xohuayan, encontramos que el número de viviendas de dos niveles, construidas en mampostería, son muy numerosas y sobresalen en relación con la antigua vivienda maya de la zona.

Esta situación nos lleva a analizar la manifestación más clara del producto de la emigración: las remesas familiares. Los montos de estos envíos han venido creciendo significativamente: durante el último año del lapso comprendido entre 2003 y 2007, se registra un crecimiento mayor a $100 \%$. Este hecho, que para el estado de Yucatán representa un cambio importante e inédito en cuestión migratoria dimensionado a nivel espacial, en lo que se refiere al envío de remesas de migrantes internacionales en México, denota, sin embargo, un patrón de autocorrelación a valores bajos-bajos (Góngora Gómez, 2007:56). También es pertinente destacar que hacia mediados de los años noventa, las remesas que llegaban a Yucatán como envíos familiares alcanzaban apenas once millones de dólares y que, para 2006, manifestaban ya en su monto un incremento porcentual de casi 900\% (Góngora Gómez, 2007:59).

15. Procesos de este tipo de cambio social y cultural en la península de Yucatán han sido estudiados con acierto por Othón Baños Ramírez, especialmente en el libro Modernidad, imaginario e identidad rurales, el caso de Yucatán (2003), y en otros trabajos previos, como el artículo "El hábitat maya rural de Yucatán: entre la tradición y la modernidad". 
Sin embargo, a partir de 2008 comienza un decremento significativo que se hace muy visible en 2009 , momento en que la remesas en Yucatán bajan con respecto al año anterior más de 23 o 24 millones de dólares. Lo anterior está en consonancia con la tendencia de las remesas a nivel nacional para este mismo periodo. No obstante, a pesar de la crisis económica en el país de destino, los migrantes han mantenido en una proporción importante - durante largos periodos- más de un empleo, lo cual les ha permitido enviar aún, quizás con un monto menor, la ayuda económica a sus comunidades. Es significativo el hecho de que estos migrantes, que hoy sobrepasan las 45 mil personas, se componen en su mayoría de pirámides poblacionales de edades muy jóvenes y de muy reciente asentamiento en su lugar de destino. Esta característica es muy significativa si se tiene en cuenta que los diferentes estudios sobre migración han determinado que los grupos migratorios que llevan un periodo corto en sus lugares de destino son los que envían con mayor frecuencia montos periódicos no interrumpidos de remesas familiares. Los trabajos de campo nos inducen a confirmar que este indicador está vigente en muchos de los poblados de las principales regiones expulsoras de migración internacional en Yucatán.

Tomando en cuenta el destino de los migrantes, la mayor parte de las remesas que recibe Yucatán provienen de su población asentada en el estado de California; lamentablemente, todavía no existe una serie de indicadores por municipios de destino que nos permita evaluar los niveles de comportamiento en la frecuencia y monto de remesas. Sin embargo, comparando la densidad migratoria del municipio de Oxkutzkab, anteriormente llamado "la huerta de Yucatán", se constata que, siendo el que registra el mayor número de migrantes, es también el que recibe el más alto monto de remesas. ${ }^{16}$

16. Desde hace más de un decenio, la ciudad de San Francisco, California, se ha convertido en el centro receptor más importante de la migración yucateca a Estados Unidos. El núcleo más numeroso de estos migrantes proviene de Oxkutzkab. Conformados por una gran mayoría de jóvenes llegan a vivir a esta ciudad de Estados Unidos en condiciones de hacinamiento que demeritan su integridad; uno de los principales objetivos de estos jóvenes es enviar remesas a sus familias para construir - en un tiempo prudencial - una vivienda; difícilmente alcanzarían estos propósitos trabajando una veintena de años en su lugar de origen (Adelson, 2002). 
Dadas las condiciones de la información, tampoco es posible por el momento extraer patrones para entender en qué medida "los motores de arranque" en el lugar de destino atraen a la población de determinadas comunidades; análisis de este tipo permitirían evaluar el impacto de conductas semejantes o disímiles en el envío de remesas. ${ }^{17}$ De cualquier manera, recordemos que, al margen de estas remesas, las familias y comunidades reciben otros "apoyos salariales"; tal es el caso de los migrantes temporales o ya establecidos que viven en la Riviera maya y los que más recientemente han migrado temporal o definitivamente a Mérida, capital del estado.

Las remesas en Yucatán han servido para mitigar la pobreza y como política de sobrevivencia, como lo explican algunos estudiosos de la migración internacional. Es evidente que no existe un modelo de desarrollo basado en las remesas, sino apenas un modelo de crecimiento que para el caso de Yucatán ni siquiera alcanza este rango, sino sólo el de sobrevivencia y, de manera distintiva, aunque sólo para algunos casos, el del aumento en la calidad de vida manifestado mediante una acumulación de salarios: lograr los ingresos que alcanzan algunos migrantes en Estados Unidos en un tiempo "prudencial", llevaría más del cuádruple de años en el lugar de origen. Tanto García Zamora (2008) como Delgado Wise y Márquez (2006:121-137), por distintas vías, concuerdan en afirmar que las remesas son un componente mayoritariamente salarial destinado a la sobrevivencia de la población:

las remesas son entonces la forma en que esta fracción del salario migrante se transfiere a sus familias y comunidades de origen para la reproducción social de la familia y la comunidad, como lo hace cualquier otro ingreso salarial en esas mismas comunidades (u otras). Las remesas son, sin duda, un fondo salarial, ese es su significado y función como variable macroeconómica (García Zamora, 2008: 435).

17. Algunos trabajos como los de Naomi Adelson (2002), Juan Rodríguez Gal et al. (2007) y Garance Burke (2002) dan cuenta de este hecho para algunas comunidades migrantes muy específicas del estado de Yucatán. 


\section{CONCLUSIÓN}

La magnitud que puede adquirir el fenómeno migratorio en el futuro próximo es preocupante si no se planifica, desde el Estado nacional y los gobiernos locales - en este caso el de Yucatán-, un desarrollo endógeno local partiendo de las potencialidades económicas, como puede ser repotencializar la apicultura, los frutales y hortalizas, y creando nuevos desarrollos tecnológicos en los que no necesariamente la inversión de capital nacional o extranjera adquiera la mera función de maquila para la utilización de la mano de obra desocupada. "Veo la migración como una manera de armarse para traer beneficios, para prevenir la migración", decía un migrante. Los migrantes yucatecos que regresan temporalmente son ya muy escasos, especialmente por los costos y los riesgos que implica atravesar la frontera. Ante esta situación, surge una pregunta: ¿podría cumplirse en un futuro próximo el sueño del migrante que legítimamente quiere regresar a establecerse y trabajar en su tierra?

La tendencia nacional de la circularidad migratoria, entre la partida y el retorno, comienza a resquebrajarse: la crisis del desempleo en Estados Unidos y las medidas extremas de seguridad que este mismo país implementa día con día dificultan el paso irregular en las fronteras. En Yucatán también empieza a percibirse este mismo fenómeno: en este último año no se ha dado el retorno, pero tampoco se percibe un nuevo movimiento migratorio trasnacional.

En la actualidad, el gobierno del estado de Yucatán está preocupado por fortalecer las vulnerabilidades del migrante, en su mayoría indocumentado que vive en Estados Unidos -durante uno de sus periodos recesivos más graves en más de medio siglo-, creando instrumentos que le permitan sobrellevar esta calidad migratoria, pero no existen políticas públicas de largo plazo encaminadas a analizar otros ángulos para un desarrollo sustentable que permita visualizar nuevos proyectos educativos de calidad e incorporar a futuro mano de obra calificada que considere los espacios desde los que emerge el mayor flujo migratorio. Lamentablemente, lo que en esta institución se considera "políticas públicas" son meros paliativos a un modelo económico que está incapacitado para la creación de nuevos empleos, que sería la barrera indispensable para detener las oleadas inmigratorias fuera de las fronteras del país. 


\section{REFERENCIAS}

Adelson, Naomi (2002), "La nueva migración indígena: los mayas de San Francisco", Revista Masiosare, núm. 255, 10 de noviembre, Suplemento dominical del periódico La Jornada, México, en http://www.jornada.unam. $\mathrm{mx} / 2002 / 11 / 10 / \mathrm{mas}-$ naomi.html

BAÑos Ramírez, Otón (2002), "El hábitat maya rural de Yucatán: entre la tradición de la modernidad", Relaciones, número 92, vol. XXIII, Zamora, El Colegio de Michoacán.

(2003), Modernidad, imaginario e identidad rurales, el caso de Yucatán, Colegio de México, Centro de Estudios Sociológicos, México, El Colegio de México.

Barajas Escamilla, Ma. del Rocío (2008), "Desarrollo e Innovación: una mirada alterna a la problemática de la migración en México", 7 mo Seminario Regional de Innovación. Migración y Desarrollo: Hacia políticas públicas innovadoras en México, Tijuana, Colef en www.foroconsultivo.org.mx/eventos_realizados/7o_innovacion/presentaciones/dra_barajas.pdf.

Boletín del Consejo Nacional de Población (1993), "Comentarios a la Encuesta internacional sobre Migración en la Frontera Norte de México", año 3, México.

Burke, Garance (2002), "Yucatecos y chiapanecos en San Francisco: inmigrantes indígenas forman comunidades y crean nuevos nichos en un mercado laboral contraído", Congreso Indígenas Mexicanos, Migrantes en Estados Unidos: Construyendo Puentes entre Investigadores y Líderes Comunitarios, Santa Cruz, Latin American and Latino Studies Department (LALS), University of California.

Bustamante, Jorge A. (2000), "Migración irregular de México a Estados Unidos: 10 años de investigación del proyecto Cañón Zapata" en Revista Frontera Norte, vol. 12, núm. 23, Tijuana, Colef.

Calderón Aragón, Georgina (2006), "La inserción del capital en los espacios rurales e indígenas en México" en Cidade, campo e turismo, Sâo Paulo, Clacso.

Castilla Ramos, Beatriz y Beatriz Torres Góngora (1998), "Algunos aspectos de la reestructuración productiva en los establecimientos manufactureros yucatecos", Cotidiano, núm. 89, México, UAM-Atzcapozalco.

Cornelius Wayne, Fitzgerald David and Lewin Fisher Pedro (2007), Mayan Journeys: The new migration from Yucatan to the United States, La Jolla, Center for Comparative Immigration Studies, UCSD.

Delgado Wise, Raúl y Humberto Márquez (2006), "Dimensiones críticas de la problemática de la migración y el desarrollo en México" en Theomai. 
Estudios sobre Sociedad, Naturaleza y Desarrollo, núm. 14, Buenos Aires, Universidad Nacional Quilmes.

García Zamora, Rodolfo (2008), "Migración internacional, remesas y desarrollo: del mito a la realidad", en América Latina en movimiento, año XXXll, 11 época, núm. 435, Quito, ALAI, Ecuador.

Góngora Gómez, Jorge Luis (2007), Dimensión espacial de las remesas migrantes internacionales en México, tesis de Maestría CRIM-UNAM/ UAEM, Cuernavaca, en http://132.248.35.1/bibliovirtual/Tesis/Gongora/

Gravel, Natalie (2006), "Los factores de retención de la maquila: lección de Yucatán (1995-2005)" en Revista Desacatos, núm. 021, México, CIESAS.

Guzmán Ayala, Estela (2007), "Autodiagnóstico participativo y migración", Expo-Feria Yucatán, Mérida, Instituto Nacional de las Mujeres/ Red para la atención de mujeres afectadas por el fenómeno migratorio, zona Sur/ Sedesol.

Guzmán, Estela, Pedro Lewin (2006), “La política pública ante los espacios binacionales de la migración yucateca” en Primer Foro sobre Migración Indígena, Mérida.

Iglesias, Esther (1988), “Yucatán al desnudo después del huracán”, inédito. (2000), "Orígenes y efectos de la deshenequenización o el desmantelamiento de una región rural", $\chi$ World Congress of Rural Sociology, Río de Janeiro.

Indemaya (2004), Encuesta sobre Migración, Mérida, Gobierno del Estado de Yucatán.

(2010), Breve estudio de la presencia de yucatecos en los Estados Unidos de Américas por matrículas consulares otorgadas, Mérida, Gobierno del Estado de Yucatán.

Indemaya, UTM y COBAY (2010), Estudio Regional de la Migración en el estado de Yucatán, Presentación de Power point, Mérida Gobierno del Estado de Yucatán en http://www.indemaya.gob.mx/pdf/estudioregionalde la migración,pdf

inegi (2000), Censo General de Población y Vivienda, México.

(2005), Conteo General de Población y Vivienda. Principales resultados por localidad, ITER, México.

(2004), Sistema de cuentas Nacionales. Producto Interno Bruto por Entidad Federativa 1997-2002, México.

(2010), Sistema de cuentas Nacionales. Producto Interno Bruto por Entidad Federativa 2005-2009, México.

(2010), Censo General de Población y Vivienda, México. 
LEVINE, Elaine (2005), "El proceso de incorporación de inmigrantes mexicanos a la vida y el trabajo en Los Ángeles, California”, Migraciones Internacionales, vol. 3, núm. 2, Tijuana, Colef.

López Villar, Darío Antonio (2005), “La migración de la población hablante de lengua indígena en el sureste mexicano", Población y Salud en Mesoamérica (revista electrónica), vol. 2, núm. 2, San José, Costa Rica, Centro Centroamericano de Población, Universidad de Costa Rica.

Lozano Ascencio, Fernando (2001), "Migración y cambio social, nuevos orígenes de la migración mexicana a los Estados Unidos: migrantes urbanos versus migrantes rurales", Scripta Nova, Revista Electrónica de Geografía y Ciencias Sociales, núm. 94 (Número extraordinario dedicado al III Coloquio Internacional de Geocrítica. Actas del coloquio), Barcelona, Universidad de Barcelona.

MendozA, Jorge Eduardo (2006), "Determinantes Macroeconómicas Regionales de la Migración Mexicana”, Migraciones Internacionales, vol. 3, núm. 4, Tijuana, Colef.

Ojeda Cerón, Carlos Rubén (1988), Migración internacional y cambio social: el caso de Peto, tesis de licenciatura en Ciencias Antropológicas, Mérida, Universidad Autónoma de Yucatán.

Pimienta Lastra, Rodrigo (2006), "Los procesos migratorios en los estados de la región sur-sureste de México”, Análisis Económico, núm. 46, vol. XXI, primer cuatrimestre de 2006, México, UAM Azcapotzalco.

Rosales Mendoza, Adriana Leona (2009), "Conceptos culturales, género y migración entre mayas yucatecos en Cancún, Quintana Roo” en Estudios de Cultura Maya, núm. XXXIII, México, IIF UNAM.

Re Cruz, Alicia (1996), "Una comunidad maya en Yucatán: Transformación social y expresión simbólica”, Revista Española de Antropología Americana, núm. 26, Madrid, Servicio de Publicaciones UCM.

RAmírez Carrillo, Luis Alfonso (2004), Las redes del poder: corrupción, maquiladoras y desarrollo regional en México. El caso de Yucatán, Cámara de Diputados, México, UADY/ Miguel Ángel Porrúa.

Rodríguez de la Gala, Juan, Vanesa Molina y Daisy García (2007), "Migración y Desarrollo Local" en Mayan Journeys: The new migration from Yucatan to the United States, La Jolla, California, Center for Comparative Immigration Studies, UCSD.

Sierra Sosa, Ligia Aurora (2006), "Migración y trabajo en el Caribe mexicano. Entre dos mundos, las familias mayas y el turismo masivo," CDI, México en 
www.cdi.gob.mx/sicopi/migracion_ago2006/1_ligia_aurora_sierra_sosa.pdf Silva, Travis et al. (2007), "Tunkás: A New Comunity of Emigration, en Mayan Journeys: The new migration from Yucatan to the United States, La Jolla, California, Center for Comparative Immigration Studies, UCSD.

García, Ángela y Alex Romero (2007), “Tunkaseño settlement in United States" en Mayan Journeys: The new migration from Yucatan to the United States, La Jolla, California, Center for Comparative Immigration Studies, UCSD.

Unger, Kurt et al. (2000), El desarrollo de las regiones de origen de los migrantes: experiencias y perspectivas, México, Conapo y Secretaría de Relaciones Exteriores. 